\title{
Distance perception in a natural outdoor setting: is there a developmental trend to overconstancy?
}

\author{
José A. Da Silva ${ }^{1}$, Elton H. Matsushima², \\ J. Antonio Aznar-Casanova ${ }^{3}$, and Nilton P. Ribeiro-Filho ${ }^{4}$ \\ ${ }^{1}$ Universidade de São Paulo at Ribeirão Preto, Brazil \\ ${ }^{2}$ Universidade Federal Fluminense, Niterói, Brazil \\ ${ }^{3}$ Universidad de Barcelona, Spain \\ ${ }^{4}$ Universidade Federal do Rio de Janeiro, Brazil
}

\begin{abstract}
The main purpose of the present study was to investigate whether in natural environment, using very large physical distances, there is a trend to overconstancy for distance estimates during development. One hundred and twenty-nine children aged 5 to 13 years old and twenty-one adults (in a control group), participated as observers. The observer's task was to bisect egocentric distances, ranging from 1.0 to $296.0 \mathrm{~m}$, presented in a large open field. The analyses focused on two parameters, constant errors and variable errors, such as measuring accuracy and precision, respectively. A third analysis focused on the developmental pattern of shifts in constancy as a function of age and range of distances. Constant error analysis showed that there are two relevant parameters for accuracy, age, and range of distances. For short distances, there are three developmental stages: 5-7 years, when children have unstable responses, 7-11, underconstancy, and 13 to adulthood, when accuracy is reached. For large distances, there is a two-stage development: 5-11 years, with severe underconstancy, and beyond this age, with mild underconstancy. Variable errors analyses indicate that precision is noted for 7 year-old children, independently of the range of distances. The constancy analyses indicated that there is a shift from constancy (or slightly overconstancy) to underconstancy as a function of physical distance for all age groups. The age difference is noted in the magnitude of underconstancy that occurs in larger distances, where adults presented lower levels of underconstancy than children. The present data were interpreted as due to a developmental change in cognitive processing rather than to changes in visual space perception.
\end{abstract}

Keywords: visual perception, space perception, perceptual development, psychophysics, child psychology, egocentric distance

El principal objetivo de este estudio fue investigar si en un medio natural, empleando distancias físicas muy grandes, hay una tendencia a sobre-constancia para las estimaciones de distancias durante el desarrollo evolutivo. Participaron como observadores 129 niños de edades entre 5 y 13 años y 21 adultos (en un grupo control). La tarea de los observadores consistió en biseccionar unas distancias egocéntricas, que variaban entre 1,0 y $296,0 \mathrm{~m}$, presentadas en un gran campo abierto. El análisis se centró en dos parámetros, error constante y error variable, de la exactitud y precisión de medida, respectivamente. Un tercer análisis se centró en el patrón evolutivo de cambios en la constancia en función de la edad y el rango de distancias. El análisis de los errores constantes mostró que hay dos parámetros relevantes para la precisión, edad y rango de distancias. Para distancias cortas, hay tres fases evolutivas: 5-7 años, cuando los niños dan respuestas inestables, 7-11, infra-constancia, y 13 años hasta la adultez, cuando alcanzan la exactitud (constancia). Para las distancias largas, hay un desarrollo de dos fases: 5-11 años, con infra-constancia severa, y más allá de esta edad, con ligera infraconstancia. El análisis del error variable indica que se alcanza precisión a partir de 7 años, con independencia del rango de distancias. En análisis de la constancia indica que existe un cambio desde la constancia (o una ligera sobre-constancia) a infra-constancia en función de la distancia física para todos los grupos de edad. La diferencia de edad se nota en la magnitud de la infra-constancia que ocurre en las distancias más largas, donde los adultos presentaban niveles menores de infra-constancia que los niños. Estos datos se interpretan como debidos a un cambio evolutivo en el procesamiento cognitivo más que a cambios en la percepción visual del espacio. Palabras clave: percepción visual, percepción del espacio, desarrollo perceptivo, psicofísica, psicología infantil, distancia egocéntrica

This research was supported by grants from Fundação de Amparo à Pesquisa do Estado de São Paulo - FAPESP No. 82/0033-6.

Correspondence concerning this article should be sent to José Aparecido Da Silva. Departamento de Psicologia e Educação, Faculdade de Filosofia, Ciências e Letras de Ribeirão Preto, Universidade de São Paulo, Avenida Bandeirantes, 3900, CEP: 14040-901, Vila Monte Alegre, Ribeirão Preto, SP, Brazil. Phone: +55 1636333728. Fax: +55 16 36333728. e-mail: jadsilva@ffclrp.usp.br 
The main purpose of this investigation was to compare the distance estimates in bisection tasks accomplished by children and adults. One may assume that the younger the children, the larger the perceptual error in judgments of distance; conversely, the older the children, the smaller the error. For adolescents and adults, whose perceptual behavior tends to overconstancy, one may expect even smaller errors.

Nevertheless, many experimental variables may influence distance estimates. For example, experiments in outdoor environments (Da Silva \& Rozestraten, 1979; Gibson, Bergman, \& Purdy, 1955; Miskie, Dainoff, Sherman, \& Johnston, 1975; Teghtsoonian \& Teghtsoonian, 1970) and in laboratories (Künnapas, 1960; Teghtsoonian \& Teghtsoonian, 1969; Teghtsoonian \& Teghtsoonian, 1978) differ in their results. Only one investigation on distance scaling was carried out with children as observers, whose ages ranged from 8 to 12 years old. Teghtsoonian and Beckwith (1976) asked them (including a control sample of 18-year-old adults) to produce magnitude estimates of distances up to $15.2 \mathrm{~m}$. Their results suggested underconstancy in distance estimates for children up to 10 years.

We also intended to verify whether this level of underconstancy was age-dependent and range-dependent, for younger children may show constancy in short distances, as predicted by Wohlwill's hypotheses $(1963,1970)$. His hypotheses also predicted that children's judgments could show underconstancy, and the younger ones would show higher levels of underconstancy. If Teghtsoonian and Beckwith's (1976) investigation had used larger distances than their largest one $(15.2 \mathrm{~m})$, children might show higher levels of underconstancy. In fact, when comparing judgments of short distances to judgments of larger distances, it was found that 8-10-year-old children increasingly showed compression of mean judgments, whereas 12-16-year-olds increasingly showed expansion of distance judgments. Thus, as indicated by the pattern of responses, their results showed a developmental tendency that could be made more explicit if distances larger than $15 \mathrm{~m}$ were estimated by observers.

Another purpose of the present investigation was to verify, by means of the fractionation method, as suggested by Harway (1963) and Collins (1976), whether a variability index, or judgment precision, increases with age and diminishes with physical distance. Gibson (1969) suggested that this increase in judgment precision with age is characteristic of performance in perceptual tasks. However, experimental evidence is not conclusive. There is evidence that suggests that adults' judgments are more variable than children's (e.g., Siegel \& McBurney, 1970), and other evidence suggesting the opposite (Bond \& Stevens, 1969). There are studies that state that there is no difference at all in children and adults' precision judgments (Teghtsoonian \& Beckwith, 1976). Nevertheless, the magnitude estimation method is not well suited to children younger than eight years old. Considering this aspect, Teghtsoonian (1980) used a cross-modality matching task (sound-to-line-length and line-length-to-sound) with children aged 4, 6, 8, and 12 years, and with adults as a control group. Results showed no differences in exponents of power functions between ages, but showed higher levels of precision for the older participants-12-year-olds and adults-compared to the younger ones. Zwislocki and Goodman (1980) studied 5and 6-year-olds compared to adults in line length estimates and they also found differences only in judgment variability, also larger for children.

The present investigation used a fractionation method, specifically a bisection task. A bisection task involves perceiving a spatial interval and dividing it by a central mark (Fischer, 2001). Several investigations have been carried out to gain a complete understanding of the underlying processes of bisection tasks and the related factors, such as sex effects, age effects, and performance methods (Jewell \& McCourt, 2000). These studies indicated that this kind of perceptual judgment seems to comprise an impressive range of cognitive operations. Some evidence pointed out that attentional and perceptual factors, instead of aspects related to stimuli orientation, determine observers' responses (Milner, Brechmann, \& Pagliarini, 1992). Thus, a bisection task is a visual measure sensitive to attentional and motor bias either in normal or in pathological observers (Jewell \& McCourt; McCourt \& Olafson, 1997; Milner et al.). According to these findings, one can determine maturational processes related to cognitive development through measures and responses provided by bisection tasks comparing different age groups, such as adults and children.

\section{Method}

\section{Participants}

One hundred and twenty-nine observers from five age groups participated in this study: 21 observers from 5 to 7 years old ( $M=6.2$ years), 31 observers from 7 to 9 years old ( $M=7.9$ years), 28 observers from 9 to 11 years old ( $M=9.1$ years), 28 observers from 11 to 13 years old $(M$ $=11.1$ years $)$, and 21 observers from 18 to 25 years old $(M$ $=20.1$ years), which was a control group of adults. All of them presented normal or corrected-to-normal visual acuity (20/20, measured in a Bausch \& Lomb Ortho-Rater). None of them had participated in similar experiments.

\section{Experimental Setting and Apparatus}

The experimental environment was an open-field, dimensions $300 \mathrm{~m}$ depth $\times 35 \mathrm{~m}$ wide, providing a full-cue condition to distance judgments. Observers remained seated in a height-adjustable chair, viewed the experimental scene binocularly, and rested their heads on a chin rest, $1.2 \mathrm{~m}$ high, in front of a $.29 \times .26 \mathrm{~m}$ window that controlled visual 
access to the experimental scene. This window could be manually closed, preventing observers from seeing the assistants changing target locations and measuring judgments.

Targets were yellow wooden triangles that varied in size to attenuate angular size information. One of them was 14.7 $\times 13.0 \mathrm{~cm}$ (base $\times$ height) and was placed at physical distances of 1.0, 2.0, and $4.0 \mathrm{~m}$; another was $19.0 \times 17.0$ $\mathrm{cm}$, and was placed at 8.0 and $16.0 \mathrm{~m}$; a third one was 52 $\times 45 \mathrm{~cm}$, and was placed at 32.0 and $64.0 \mathrm{~m}$; a fourth one was $59.5 \times 52.0 \mathrm{~cm}$, and was placed at $128.0 \mathrm{~m}$; and the last one was $105.0 \times 120.0 \mathrm{~cm}$, and was placed at distances 256.0 and $296.0 \mathrm{~m}$. These triangles were built following findings of Rozestraten and Da Silva (1977). Nevertheless, small differences in visual angles are not relevant to distance perception, either because of the absence of size constancy (Teghtsoonian \& Beckwith, 1976), or because (egocentric) distance perception is considered an independent process of size perception (although the opposite is not true; that is, size perception requires knowing the egocentric distance to the perceived object) (Gogel, 1993; Haber \& Levin, 2001).

Three yellow bars were used as bisector stimuli. For distances from 1.0 to $16.0 \mathrm{~m}$, a $30-\mathrm{cm}$ long $\times 1.2-\mathrm{cm}$ wide bar was the bisector stimulus. Another bar, 100-cm long $\times$ $7.5-\mathrm{cm}$ wide, was the bisector stimulus for 32.0, 64.0, and $128.0 \mathrm{~m}$ distances, and a $100-\mathrm{cm}$ long $\times 11-\mathrm{cm}$ wide bar was the bisector stimulus for 256.0 and $296.0 \mathrm{~m}$ distances. These bars were moved by assistants as indicated by the observers. See Figure 1.

\section{Procedures}

The observers' task was to divide into two equal parts the distances to the stimuli adjusting the position of a bisector stimulus. Stimuli were presented in a fixed order for all observers $(32.0,296.0,1.0,2.0,256.0,64.0,16.0$, $4.0,128.0$, and $8.0 \mathrm{~m}$ ), in both bisection directions (ascending and descending).
Results

\section{Constant Errors Analyses: Accuracy of Estimates}

Individual bisections were transformed into constant errors with the following equation:

$$
C n t E r=B-\left(\frac{P D}{2}\right)
$$

where $B$ is the bisection and $P D$ is the physical distance, and then submitted to a three-way ANOVA (5 Age Groups $\times 10$ Physical Distances $\times 2$ Bisection Directions).

Mean constant errors and standard deviations are summarized in Figure 2. One can readily see that, for short distances, all age groups presented small errors that increased with distance. Adults' errors remained small up to $64.0 \mathrm{~m}$, at which point they increased systematically. The same tendency occurred with children as of $16.0 \mathrm{~m}$.

ANOVA revealed significant differences for physical distances, $F(9,1116)=582.603, p=.000$, age groups, $F(4$, $124)=7.618, p=.000$, and for interaction age groups $\times$ physical distances, $F(36,1116)=5.086, p=.000$. Post hoc Tukey HSD analyses comparing age groups revealed significant differences between adults and children from the following age groups, 5-7 years $(p=.000), 7-9$ years $(p=$ $.000)$, and 9-11 years $(p=.000)$.

Results from ANOVA and Tukey HSD analyses indicated that accuracy in bisections is a function of the physical distance to the stimulus and the observer's age. Children up to 11 years presented severe undershooting in their responses, whereas older children presented this magnitude of undershooting only for distances beyond $64.0 \mathrm{~m}$. Adults' judgments were more accurate up to $128.0 \mathrm{~m}$, showing undershooting beyond this distance. Results also indicated a transition age, circa 11 years, when there may be some sort of developmental change towards higher levels of accuracy in space perception.
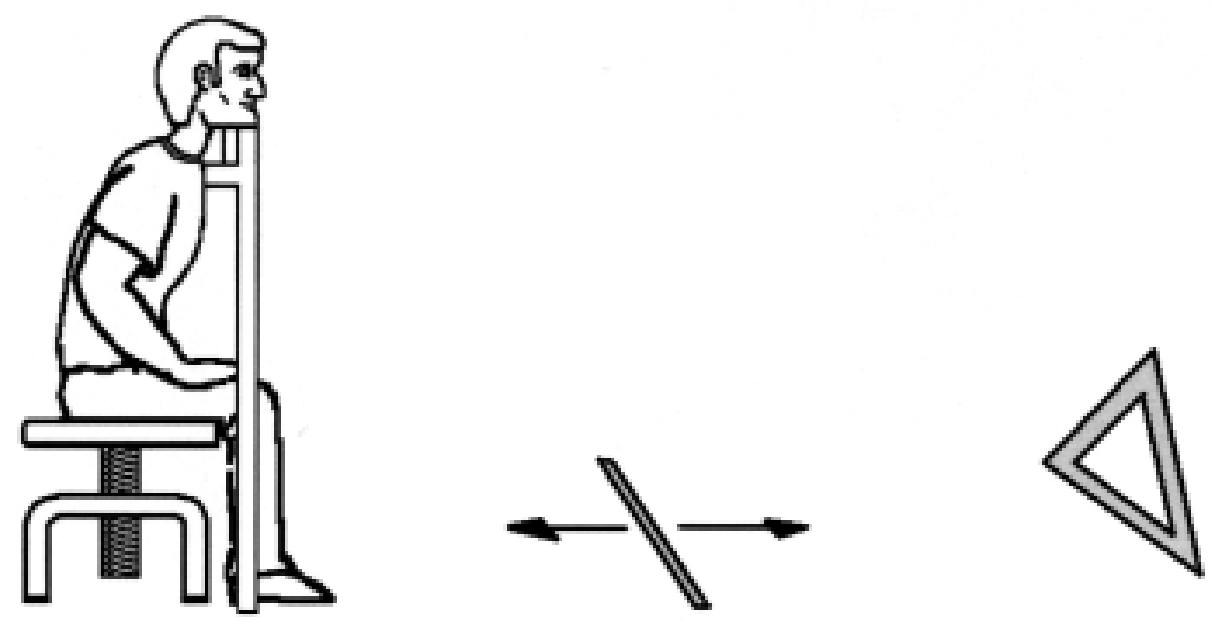

Figure 1. Experimental environment. 


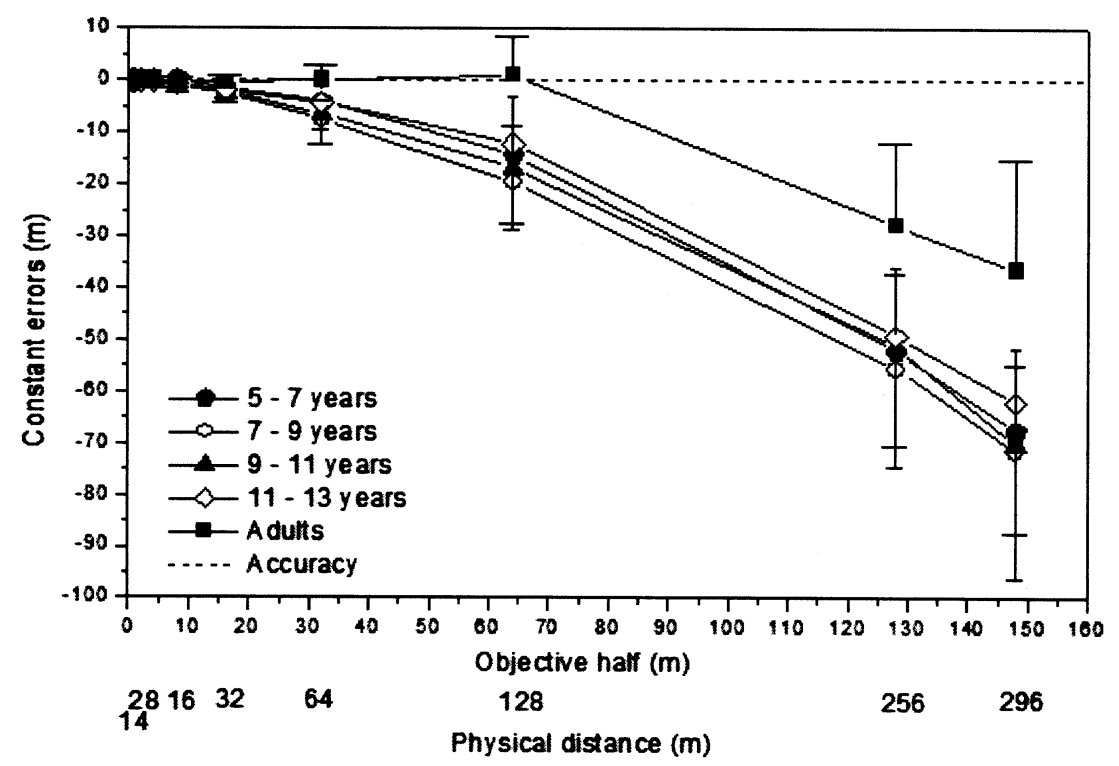

Figure 2. Mean constant errors and their standard deviations as a function of objective halves of physical distances, in meters. Dotted line represents accuracy. Standard deviation bars are depicted in one direction for better readability.

\section{Analyses of Estimates of Distances up to $16.0 \mathrm{~m}$}

Estimates up to $16.0 \mathrm{~m}$ showed systematic errors for all age groups. Positive constant errors (overshooting) were found for 5-7-year-old children, whereas 7-13-year-olds produced negative constant errors (undershooting). One can see that 7-9-year-olds and 9-11-year-olds presented the same pattern of responses. Adults produced accurate responses as can be seen in Figure 3.

A three-way ANOVA produced significant differences for physical distances, $F(4,496)=6.276, p=.000$, age groups, $F(4,124)=5.528, p=.000$, and for interaction Physical Distances $\times$ Age Groups, $F(16,496)=3.171, p=.000$. Tukey HSD produced significant differences between 5-7-year-olds and 7-9-year-olds $(p=.015)$, between 5-7-year-olds and 911-year-olds $(p=.000)$, and between 9-11-year-olds and adults $(p=.018)$. This analysis indicated that, for this short range of distances, there seem to be three development stages, one from 5 to 7 years, another one between 7 and 13 years, and the third, from 13 until adulthood.

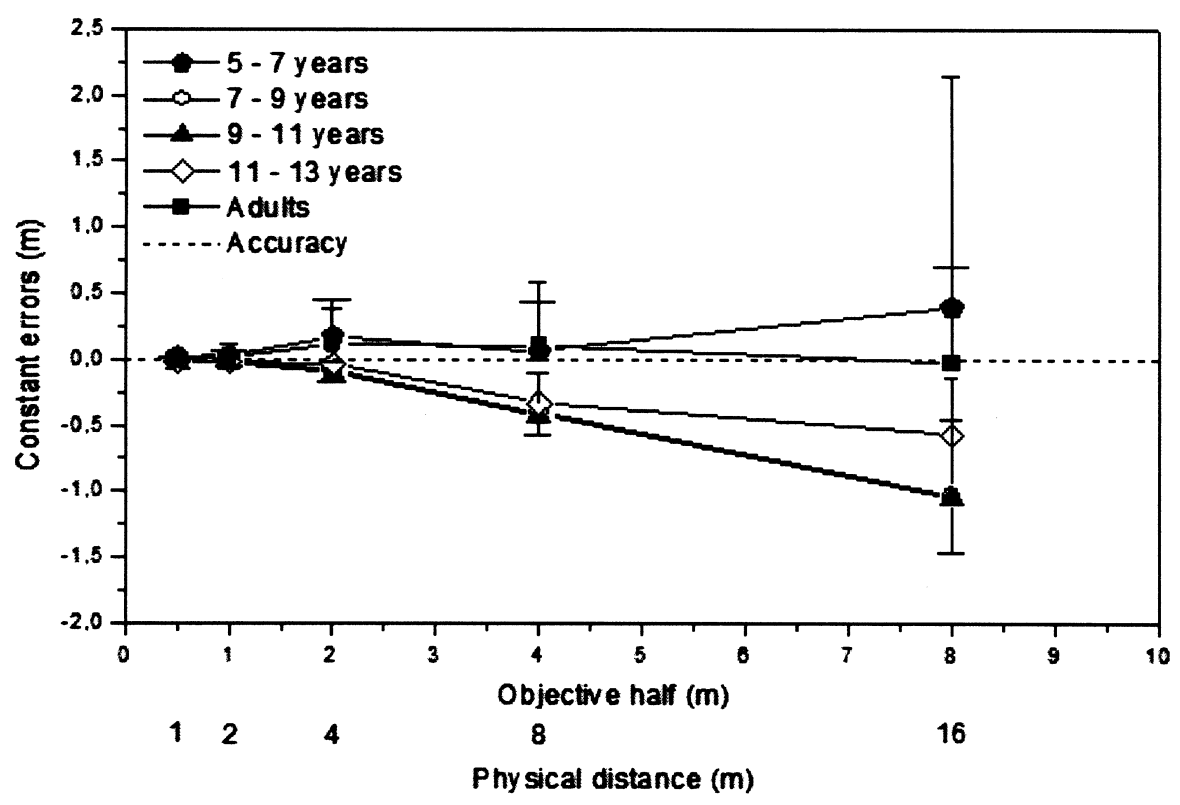

Figure 3. Mean constant errors and their standard deviations as a function of objective halves of physical distances up to $16.0 \mathrm{~m}$, in meters. Dotted line represents accuracy. Standard deviation bars are depicted in one direction for better readability. 


\section{Analyses of Estimates of Distances beyond $32.0 \mathrm{~m}$}

Analyzing distances beyond $32.0 \mathrm{~m}$, one can see smaller constant errors for adults in Figure 4. All age groups were more accurate for distances up to $32.0 \mathrm{~m}$, showing a slightly negative error of $2.5 \mathrm{~m}$. Beyond this distance, all the children (age groups from 5 to 13 years) showed undershooting. Adults remained accurate up to $128.0 \mathrm{~m}$, and showed negative and systematic errors for the two largest distances.

A three-way ANOVA showed significant differences just for main factors physical distances, $F(4,496)=569.215, p=$ .000 , and age groups, $F(4,124)=7.664, p=.000$, and for one interaction, Physical Distances $\times$ Age Groups, $F(16,496)$ $=3.877, p=.000$. Tukey HSD indicated differences between adults and the following children's groups, 5-7-year-olds ( $p=$ $.000)$, 7-9-year-olds $(p=.000)$, and 9-11-year-olds $(p=.000)$.

Analyzing this range of distances, spatial perception seems to develop fully in children over 11 years old. Accurate judgments in this range of distance probably require more cognitive skills or more experience with different environments and distances (which is more likely for older children or adults).

\section{Variable Errors Analyses: Precision of Estimates}

For the next analysis, individual bisections were transformed into variable errors as follows:

$$
\operatorname{VarEr}=\left|B_{i}-\left(\frac{\Sigma B}{2}\right)\right|
$$

where $B_{i}$ is an individual bisection, $B$ is any bisection from the age group, and $N$ is sample size of the age group. Variable error is a measure of the intrinsic variability of an experimental group.
Mean variable errors and standard deviations are summarized in Figure 5. There was a general tendency for a systematic increase in variability with increasing distances. Of relevance, children from 5 to 7 years old presented more variability than any other age group. The remaining age groups seemed to differ only in the largest distance.

A three-way ANOVA on individual variable errors showed significant differences for main factors physical distances, $F(9,1116)=274.343, p=.000$, and age groups, $F(4,124)=$ $3.784, p=.000$, and for only one interaction, Physical Distances $\times$ Age Groups, $F(36,1116)=1.531, p=.024$. Tukey HSD comparing age groups showed significant differences between adults and children from 5 to 7 years old $(p=.005)$, and from 7 to 9 years old $(p=.023)$. These results confirm visual inspection of the data and reveal a distinction between younger children (up to 9 years old) and adults.

\section{Analyses of Estimates of Distances up to $16.0 \mathrm{~m}$}

In Figure 6, which summarizes variable errors for distances up to $16.0 \mathrm{~m}$, one can observe more clearly the higher variability shown by the youngest age group (5-7 years old). This is confirmed by statistical analyses. A three-way ANOVA on individual variable errors that showed significant differences for physical distances, $F(4,496)=188.500, p=.000$, and for age groups, $F(4,124)=13.191, p=.000$, and for only one interaction, Physical Distances $\times$ Age Groups, $F(16,496)=$ $7.069, p=.000$. Tukey HSD showed that 5-7-year-olds are different from all the other age groups, 7-9-year-olds ( $p=$ $.000), 9-11(p=.000), 11-13$-year-olds $(p=.000)$, and adults $(p=.000)$. Our results suggest that 7-year-old children seem to lack the cognitive skills to produce consistent responses, or, in other words, to produce coherent judgments.

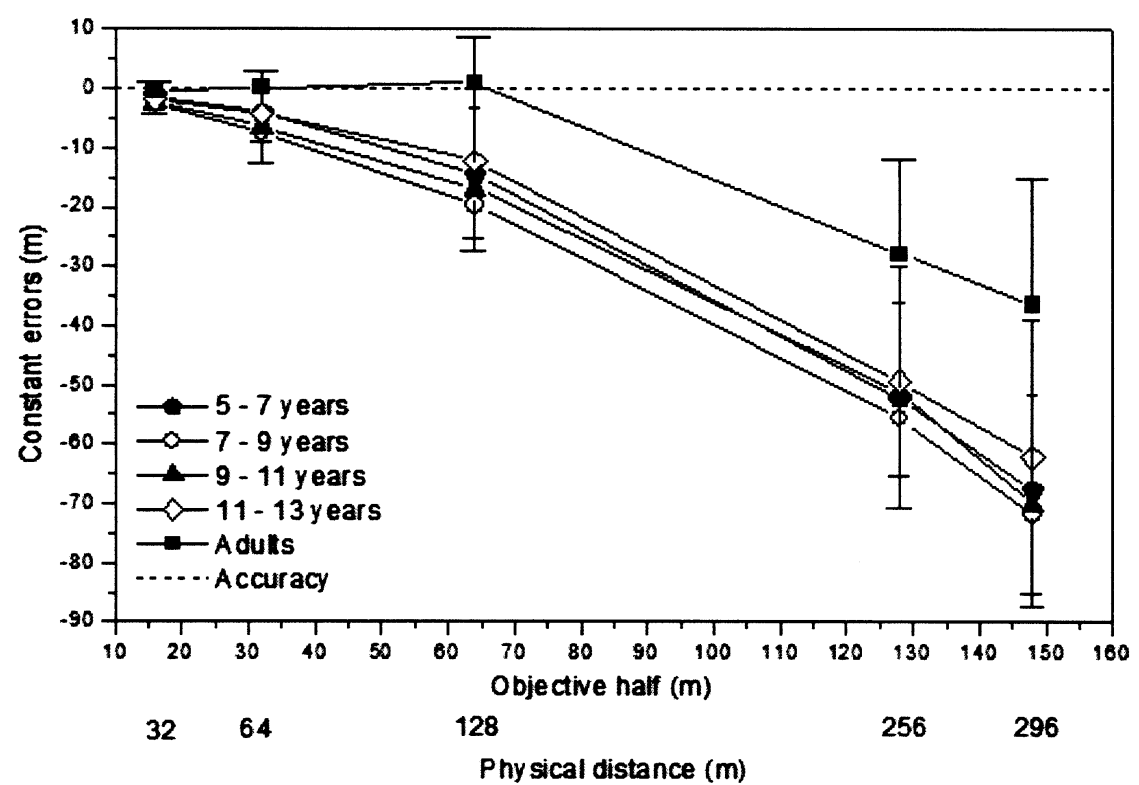

Figure 4. Mean constant errors and their standard deviations as a function of objective halves of physical distances beyond $32.0 \mathrm{~m}$, in meters. Dotted line represents accuracy. Standard deviation bars are depicted in one direction for better readability. 


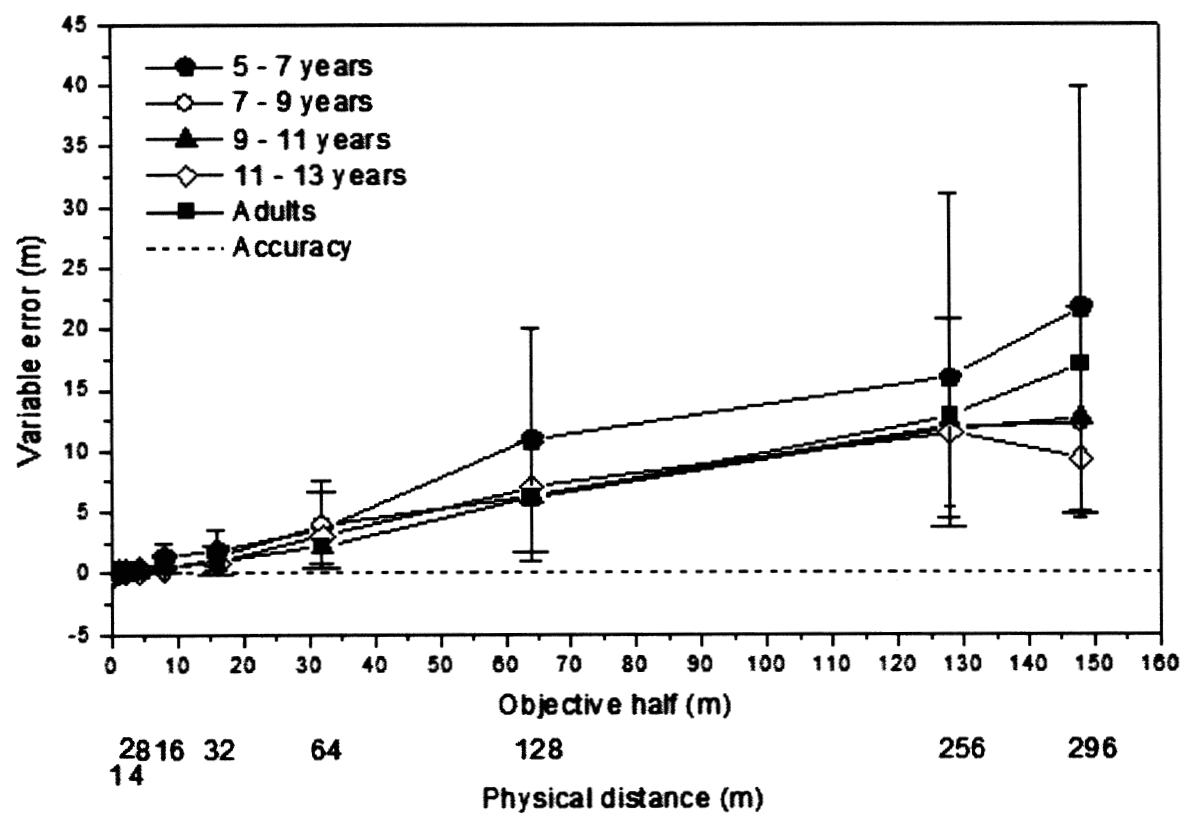

Figure 5. Mean variable errors and their standard deviations as a function of objective halves of physical distances, in meters. Dotted line represents maximum precision. Standard deviation bars are depicted in one direction for better readability.

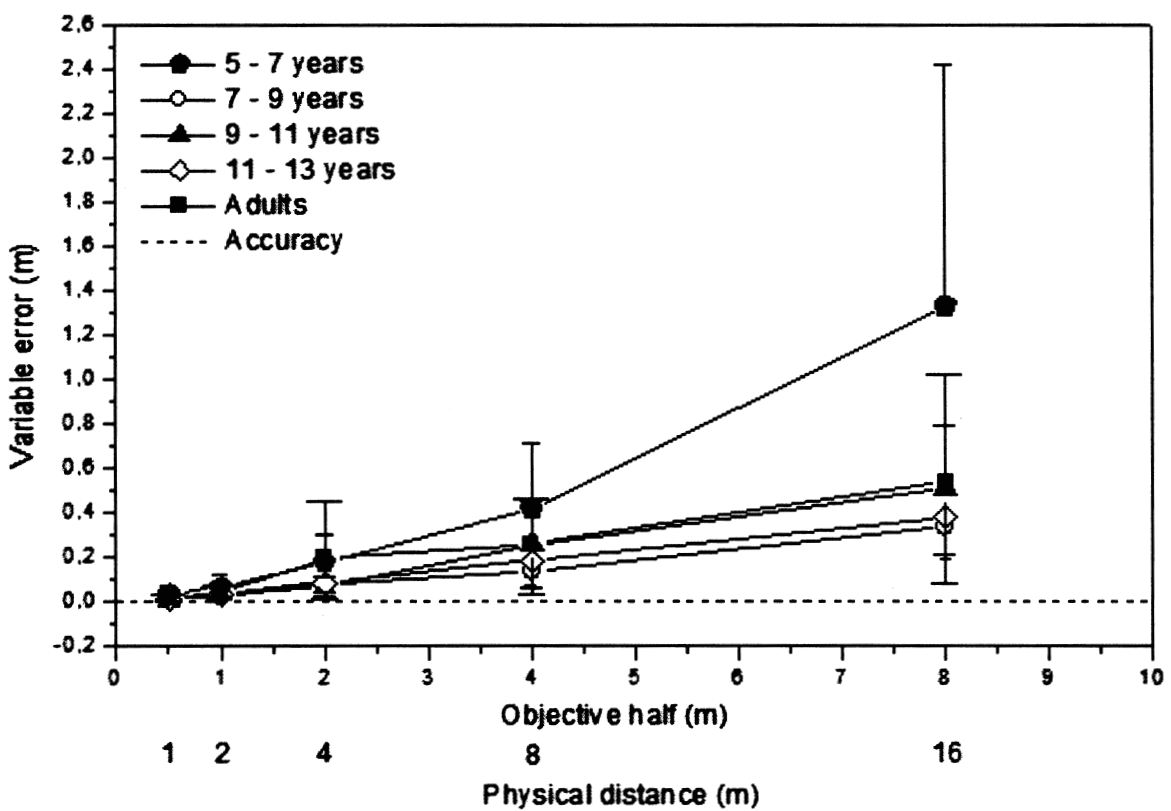

Figure 6. Mean variable errors and their standard deviations as a function of objective halves of physical distances up to $16.0 \mathrm{~m}$, in meters. Dotted line represents maximum precision. Standard deviation bars are depicted in one direction for better readability.

\section{Analyses of Estimates of Distances beyond $32.0 \mathrm{~m}$}

Observing Figure 7, which summarizes variable errors for distances beyond $32.0 \mathrm{~m}$, one can verify the same pattern of the overall analysis, namely 5-7-year-old children presented higher variability than all the other age groups. For this range of distances, the three-way ANOVA of the variable errors confirmed this observation, showing significant effects for age groups, $F(4,124)=3.512, p=.009$, and for physical distances, $F(4,496)=184.567, p=.000$. Tukey HSD on age groups presented significant differences between adults and 5-7-year-olds $(p=.009)$, and adults and 7-9-year-olds $(p=.026)$. This may indicate that precision in judgments of distances appears around the age of 9 years. 


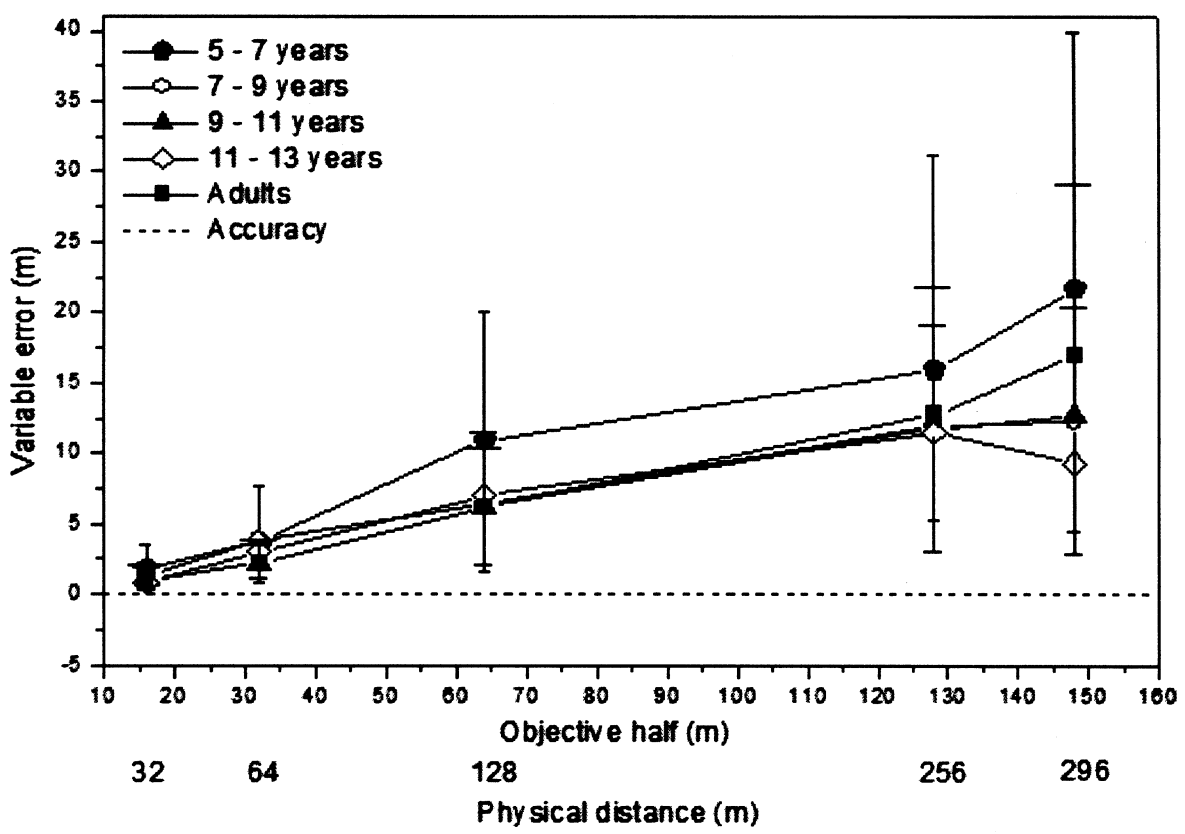

Figure 7. Mean variable errors and their standard deviations as a function of objective halves of physical distances beyond $32.0 \mathrm{~m}$, in meters. Dotted line represents maximum precision. Standard deviation bars are depicted in one direction for better readability.

\section{Analyses of the Development of Constancy Tendencies}

This analysis was aimed at testing two of the three hypotheses proposed by Wohlwill $(1963,1970)$ on the development of space perception. One of them predicts that there would be a development from underconstancy in infancy to overconstancy in adolescence, either in size perception or in distance perception. The other one says that the level of under- or overconstancy would depend on the observer's age, and also on the range of distances used to assess space perception. It predicts that perceptual constancy may arise in children for short distances and that underconstancy may appear in adults' judgments of large distances.

To verify these predictions we built frequency histograms of percent errors as a function of physical distances. We set the interval of relative errors between -2.5 and 2.5 as a reference value for constancy. Smaller and larger errors were considered as underconstancy and overconstancy, respectively, following the suggestions of Da Silva (1983). Figure 8 shows the distribution of frequencies of percent errors as a function of physical distances. Each panel shows these parameters for each age group. One can clearly verify a shift in the constancy patterns as a function of physical distances associated with the observer's development. Whereas younger age groups showed a pattern moving from constancy in short distances to severe underconstancy for large distances (with relative errors reaching 60 to $80 \%$ ), adults showed a similar pattern in structure, but showed much smaller errors for large distances than did the children: from constancy to a maximum of $40 \%$ of underconstancy.
Our analyses only partially confirmed Wohlwill's (1963, 1970) hypotheses. There really is a dependency of the level of under- and overconstancy on the range of distances, as higher levels of underconstancy can be found at large distances, and constancy and overconstancy can only be found at short distances. The first hypothesis was not completely confirmed, as adults and adolescents showed overconstancy only for a limited range of distances, up to $16.0 \mathrm{~m}$, presenting underconstancy for larger distances.

\section{Conclusion}

The development of space perception, more specifically, of accuracy and precision in distance judgments, seems to appear at different ages. One could suggest that these differences are the result of intrinsic differences, as they are independent behavioral measures of perceptual skills. One could also point out that this could be an artifact of this experiment, which was carried out using a task that requires some development of spatial and cognitive skills. We claim that these parameters may provide an explanation of the development of space perception.

Accuracy depends on the range of distances involved in the perceptual task. For short distances, there is great initial instability in judgments (5-7-year-old children), followed by a period of underconstancy (7-11-year-olds) until accuracy, which emerges between adolescence and adulthood. For large distances, a two-stage development seems to occur: severe underconstancy in childhood (5-11year-olds) followed by mild underconstancy in adolescence 

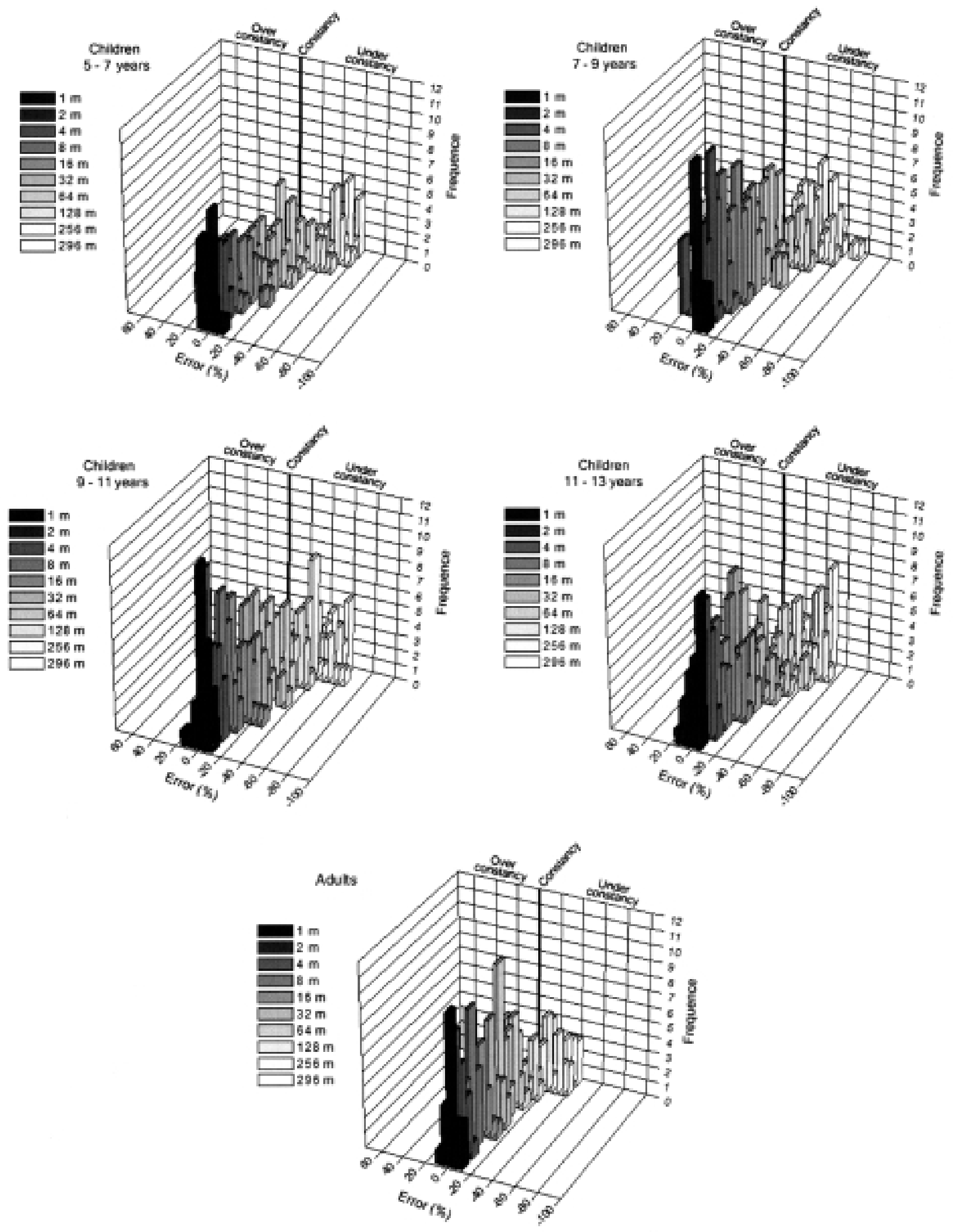

Figure 8. Frequency distributions of percent errors as a function of physical distances. Upper left panel presents distribution for 5-7-yearold children; upper right panel, for 7-9-year-old children; middle left panel, for 9-11-year-old children; middle right panel, for 11-13-yearold children; lower panel, for adults. As a reference, constancy, underconstancy, and overconstancy criteria areas are depicted in figures. 
and adulthood. These developmental patterns must be related to cognitive development because the task we used, bisection, was more cognitive-demanding than the traditional one, verbal reports. Complete development of the cognitive system is only achieved after adolescence and might be related to the observed developmental patterns.

Precision or consistency follows a different developmental pattern, an even simpler one. Precision seems to emerge at 7 years of age for any range of distances. It must reflect some sort of general cognitive ability to produce judgments. This contradicts previous suggestions about the development of precision in judgments of distance that would occur progressively up to adulthood (Gibson, 1969). Even adults are very variable, but this threshold is reached just after the $7^{\text {th }}$ year. Higher variability during infancy is a recurrent finding in visual research (Collins, 1976; Degelman, 1977; Degelman \& Rosinski, 1979; Harway, 1963).

Our results were in accord with an old statement of Piaget (1969), establishing that spatial knowledge in children develops from an unstable spatial thinking, responsible for underconstancy in youngsters, to a more stable spatial thinking, in the adult. In other words, there is a shift in the functional validity of visual space perception towards a complete correspondence between environmental information and the observer's perception (Baumberger \& Flückiger, 2004; Brunswick, 1955; Gibson, 1969). A two-process theory of perception has been proposed (Gogel, 1974; Gogel \& Da Silva, 1987), in which two separate perceptual mechanisms work synergistically to produce the observed pattern. One of these mechanisms is the environmental source of information, or visual cues, which allow accurate or nearly accurate responses for short distances. The second process is learning-dependent, which is closely related to development, and responsible for the differences in large distances. As adults have more experience with distances, objects, and goal-directed actions towards visual targets, they know much more than children do about physical spatial relations and how they appear to our senses.

\section{References}

Baumberger, B., \& Flückiger, M. (2004). The development of distance estimation in optic flow. Perception, 33, 1081-1099.

Bond, B., \& Stevens, S.S. (1969). Cross-modality matching of brightness to loudness by 5 -year-olds. Perception \& Psychophysics, 6, 337-339.

Brunswick, E. (1955). Representative design and probabilistic theory of functional psychology. Psychological Review, 62, 193-217.

Collins, J.R. (1976). Distance perception as a function of age. Australian Journal of Psychology, 28, 109-113.

Da Silva, J.A. (1983). Scales for subjective distance in children and adults in a large open field. The Journal of Psychology, $113,221-229$
Da Silva, J.A., \& Rozestraten, R.J.A. (1979). Construção de uma escala subjetiva de distância pelo método do fracionamento. Psicologia, 5, 45-58.

Degelman, D. (1977). Developmental processes and motion parallax. (Doctoral dissertation, University of Pittsburgh, 1976) Dissertation Abstracts International, 38, 389.

Degelman, D., \& Rosinski, R. (1979). Motion parallax and children's distance perception. Developmental Psychology, 15, 147-152.

Fischer, M.H. (2001). Cognition in the bisection task. Trends in Cognitive Sciences, 5, 460-462.

Gibson, E.J. (1969). Principles of perceptual learning and development. New York: Appleton-Century Crofts.

Gibson, E.J., Bergman, R., \& Purdy, J. (1955). The effect of prior training with a scale of distance on absolute and relative estimation of distance over ground. Journal of Experimental Psychology, 50, 97-105.

Gogel, W.C. (1974). Cognitive factors in spatial responses. Psychologia, 17, 213-225.

Gogel, W.C. (1993). The analysis of perceived space. In S.C. Masin (Ed.), Foundations of perceptual theory. (pp. 113-182). Amsterdam: Elsevier.

Gogel, W.C., \& Da Silva, J.A. (1987). A two-process theory of the response to size and distance. Perception \& Psychophysics, 41, 220-238

Haber, R.N., \& Levin, C.A. (2001). The independence of size and distance perception. Perception \& Psychophysics, 63, 1140-1152

Harway, N.I. (1963). Judgment of distance in children and adults. Journal of Experimental Psychology, 65, 385-390.

Jewell, G., \& McCourt, M.E. (2000). Pseudoneglect: A review and meta-analysis of performance factors in line bisection task. Neuropsychologia, 38, 93-110.

Künnapas, T. (1960). Scales for subjective distance. Scandinavian Journal of Psychology, 1, 187-192.

McCourt, M.E., \& Olafson, C. (1997). Cognitive and perceptual influences on visual line bisection: Psychophysical and chronometric analyses of pseudoneglect. Neuropsychologia, 35, 369-380.

Milner, A.D., Brechmann, M., \& Pagliarini, L. (1992). To halve and to halve not: An analysis of line bisection judgments in normal subjects. Neuropsychologia, 30, 515-526.

Miskie, D., Dainoff, M., Sherman, R., \& Johnston, L. (1975). Does distance perception change as the degree of enclosure changes: Some psychophysical studies under real and simulated conditions. Man-Environment Systems, 5, 317-320.

Piaget, J. (1969). Le développement des perceptions en fonction de l'âge. In P. Fraisse \& J. Piaget (Eds.), La Perception (Vol. VI). Paris: PUF.

Rozestraten, R.J.A., \& Da Silva, J.A. (1977). Avaliação de ângulos iguais e ângulos subjetivamente equivalentes em campo aberto. Estudos Cognitivos, 2, 5-12.

Siegel, A.W., \& McBurney, D.H. (1970). Estimations of line length and number: A developmental study. Journal of Experimental Child Psychology, 10, 170-180.

Teghtsoonian, M. (1980). Children's scale of length and loudness: A developmental application of cross-modal matching. Journal of Experimental Child Psychology, 20, 290-307. 
Teghtsoonian, M., \& Beckwith, J.B. (1976). Children's size judgments when size and distance vary: Is there a developmental trend to overconstancy? Journal of Experimental Child Psychology, 22, 23-39.

Teghtsoonian, M., \& Teghtsoonian, R. (1969). Scaling apparent distance in natural indoor settings. Psychonomic Science, 16, 281-283.

Teghtsoonian, R., \& Teghtsoonian, M. (1970). Scaling apparent distance in natural outdoor settings. Psychonomic Science, 21, 215-216.

Teghtsoonian, R., \& Teghtsoonian, M. (1978). Range and regression effects in magnitude scaling. Perception \& Psychophysics, 24, 305-314.
Wohlwill, J.F. (1963). The development of "overconstancy" in space perception. In L.P. Lipsitt \& C.C. Spiker (Eds.), Advances in child development and behavior. Vol. I (pp. 265-312). New York: Academic Press.

Wohlwill, J.F. (1970). Perceptual development. In H.W. Reese \& L.P. Lipsitt (Eds.), Experimental child psychology (pp. 31-68). New York: Academic Press.

Zwislocki, J.J., \& Goodman, D.A. (1980). Absolute scaling of sensory magnitude: A validation. Perception \& Psychophysics, 28, 28-38.

Received December 15, 2005 Review received March 4, 2006 Accepted August 24, 2006 